\title{
The citizen at the centre of ethics
}

To the Editor - A recent editorial in Nature Machine Intelligence discusses the impact of artificial intelligence on human rights and the rising resistance from tech workers against the trajectory of technological progress transforming everyday lives ${ }^{1}$. Several non-profit organizations such as the Center for Humane Technology are working to raise awareness of ethical concerns in AI among both politicians and actors in the technology sector ${ }^{2}$. However, the pressure must also come from citizens themselves, from the grassroots of our societies, as it does in the case of climate change protests.

It is up to the scientific community to communicate and popularize AI ethics issues so that citizens are better equipped to understand and question the digital technology practices that surround them. New educational concepts focused on critical thinking, creativity and inventiveness are needed. Following this perspective, in March 2017, the DQ Institute launched an initiative to promote education programmes that train people to deal with the pitfalls of digital technology. Its aim is to improve global digital skills by coordinating efforts across educational and research communities. Part of the initiative is a focus on developing digital citizenship competencies for young children such as the digital citizen identity, privacy management, screen time management, cybersecurity management, cyberbullying management, digital empathy, digital footprints and critical thinking. In another approach, the 'Truth about tech' campaign launched by Common Sense Media in collaboration with the Center for Human Technology, provides specially designed workshops for primary school pupils ${ }^{3}$. The workshops offer children the opportunity to explore issues surrounding technology addiction and how it impacts their wellbeing. Since 2018 , this campaign has visited more than 55,000 public schools in the United States, explaining to young people the influences to which they are subjected.

Popularization initiatives need to be supported and encouraged on a wide scale by the research community. To be fully effective, these initiatives must be informed by scientists in a holistic approach to AI ethics, as supported by organizations such as the AI Now Institute. Since 2017, the AI Now Institute produces interdisciplinary research and organizes symposia on the social implications of artificial intelligence and aims to act as a hub for the emerging field. By taking part in the dissemination of knowledge on subjects fundamental for society, scientists can increase the positive educational dynamics on these issues.

Encouraging politicians, economic actors and technology executives to adopt more acceptable ethics only makes sense if this willingness is supported by those most concerned: the citizens who use the products or produce the data.

Today's civil society efforts are too dispersed and small scale to be an effective counterweight to the inertia of political trends led by state actors and multinational corporations. Still, they are a source of hope and represent an early manifestation of a widespread latent desire among concerned citizens who recognize that modern societies must address ethical issues regarding data and technology with a human-centric approach.

\section{Nicolas Spatola (D)}

Laboratory of Social and Cognitive Psychology, UMR6024, CNRS, University Clermont Auvergne, Clermont-Ferrand, France.

e-mail:nicolas.spatola@uca.fr

Published online: 14 February 2020

https://doi.org/10.1038/s42256-020-0150-0

References

1. Nat. Mach. Intell. 1, 547 (2019).

2. Floridi, L. et al. Minds Mach. 28, 689-707 (2018).

3. Truth about tech. Common Sense Media https://www. commonsensemedia.org/kids-action/truth-about-tech (2020).

Competing interests

The author declares that he has no competing interests. 